\title{
Mudanças curriculares na educação superior em Odontologia: inovações, resistências e avanços conquistados
}

\author{
Juliana Maciel de Souza Lamers*; Alexandre Baumgarten**; Fernando Valentim Bitencourt***; \\ Ramona Fernanda Ceriotti Toassi****
}

* Doutoranda do Programa de Pós-Graduação em Educação da Universidade Federal do Rio Grande do Sul

** Doutorando do Programa de Pós-Graduação em Epidemiologia da Universidade Federal do Rio Grande do Sul

*** Estudante de graduação, Bolsista de Iniciação Científica, Universidade Federal do Rio Grande do Sul

**** Doutora em Educação, Professora do Programa de Pós-Graduação em Ensino na Saúde da Faculdade de Medicina, Professora adjunta do Departamento de Odontologia Preventiva e Social e Coordenadora do Núcleo de Avaliação da Faculdade de Odontologia da Universidade Federal do Rio Grande do Sul

Recebido em 03/08/2016. Aprovado em 20/10/2016.

\begin{abstract}
RESUMO
$\mathrm{O}$ artigo analisa o desenvolvimento de um currículo integrado de Odontologia orientado pelas Diretrizes Curriculares Nacionais e baseado na construção de competências em uma universidade pública no sul do Brasil. A articulação das atividades acadêmicas com o mundo do trabalho no Sistema Único de Saúde (SUS) foi uma das principais mudanças desta proposta curricular. O método de investigação foi predominantemente qualitativo, caracterizando-se como um estudo de caso. O corpus de análise constitui-se pela aplicação de questionários e realização de entrevistas individuais semiestruturadas. Participaram do estudo 59 professores, sete técnicos administrativos e três gestores do curso. Os resultados encontrados qualificam o currículo avaliado quanto à integração entre professores de diferentes departamentos e entre as áreas (interdisciplinaridade); cuidado em saúde humanizado centrado nas necessidades do indivíduo/paciente; estímulo à cidadania; ensino clínico integrado, organizado por complexidade de procedimentos; e estágios supervisionados em cenários de prática do SUS (serviços de Atenção Primária à Saúde, de média e alta complexidade, além da gestão em saúde). A integração curricular, um dos eixos estruturantes do currículo e reconhecida como uma potencialidade, também se estabeleceu como um desafio para a consolidação do processo. A qualificação docente para atuar neste currículo, bem como a avaliação curricular continuada, foram aspectos que se destacaram para o fortalecimento do curso. Potencialidades e desafios são apresentados e discutidos em relação a um modelo curricular integrado em Odontologia, apontando para a necessidade de se repensar permanentemente tal currículo, favorecendo práticas educacionais cada vez mais renovadas e democráticas.
\end{abstract}

Descritores: Avaliação Educacional. Currículo. Educação Superior. Educação em Odontologia. 


\section{INTRODUÇÃO}

O conhecimento científico, desde meados do século XX, passa por renovações com o surgimento de novas teorias que questionam o pensamento simplista e reducionista, o qual teve origem na organização disciplinar da pesquisa, descontextualizando e isolando muitos fenômenos pesquisados, separando objetos e pessoas para poder observá-los e melhor quantificá-los. Surgem assim, novos campos do conhecimento voltados para o fazer colaborativo e para o trabalho em equipe multiprofissional ${ }^{1}$.

O campo de estudos curriculares tem sido alvo privilegiado de atenção e crescimento nas últimas décadas, mostrando reformulações curriculares nos diversos graus de ensino no Brasil $^{2}$.

$\mathrm{Na}$ área da saúde, com a instituição das Diretrizes Curriculares Nacionais (DCN), os cursos de graduação passaram a buscar a superação do modelo tradicional de 'grade' curricular e organização pedagógica marcada pela fragmentação de conteúdos, evoluindo por meio de propostas articuladas e orientadas pela prática profissional vinculada ao mundo do trabalho ${ }^{3}$.

A ideia de currículos mais sensíveis às necessidades do trabalho significou escuta às práticas curriculares nos espaços em que estas ocorrem, e em outros espaços sociais nos quais se aprende saúde. Esta compreensão trouxe aos currículos a noção de espaços de aprendizagem enquanto locais que articulam, intencionalmente, processos de aprendizagem e de trabalho ${ }^{4}$ e o comprometimento do ensino com os princípios do Sistema Único de Saúde (SUS) ${ }^{5}$, tendo a integração ensino-serviço como uma ferramenta capaz de potencializar as atividades curriculares desenvolvidas no curso ${ }^{6}$.

Para os cursos de Odontologia, as DCN foram implantadas em $2002^{7}$, a partir da necessidade apontada pela Lei de Diretrizes e Bases da Educação Brasileira $(\mathrm{LDB})^{8}$. Tais
Diretrizes definiram o objetivo do curso e o currículo de base nacional comum, a ser complementado pelas instituições de ensino superior, com uma parte diversificada capaz de refletir a experiência de cada instituição flexibilização curricular - e aos condicionantes do quadro regional em que se situa ${ }^{9}$.

Na Universidade Federal do Rio Grande do Sul (UFRGS), o curso de graduação em Odontologia passou ao longo dos anos por diversas reestruturações baseadas no modelo de currículo mínimo, em 1952, 1962, 1972 e 1982. A LDB e a instituição das DCN favoreceram uma avaliação do currículo vigente no curso, o que levou à ampla discussão pela comunidade acadêmica do modelo de ensino-aprendizagem adotado. Tal processo de reestruturação curricular se concretizou, em 2005, com o então 'novo' currículo integrado do curso de Odontologia, pautado pelo panorama político do Brasil e baseado na construção de competências $^{10}$, o que envolve a preparação do estudante para um saber aplicável, saber em ação ${ }^{11}$.

A arquitetura curricular implementada trouxe inovações pedagógicas nos seguintes aspectos: Seminários de Integração da $1^{\mathrm{a}}$ a $4^{\mathrm{a}}$ etapa do curso (75 horas), associando os conteúdos das disciplinas que compõem cada uma das etapas; Acompanhamentos Clínicos da $2^{\mathrm{a}}$ à $4^{\mathrm{a}}$ etapa (90 horas), que envolvem o contato com estudantes de etapas mais avançadas, já inseridos em atividades clínicas; Clínicas Integradas da $5^{\mathrm{a}}$ à $8^{\mathrm{a}}$ etapa do curso (1005 horas), com abordagem integral ao paciente em graus crescentes de complexidade de procedimentos; e Estágios Curriculares Supervisionados no SUS, no último ano do curso $(930 \text { horas })^{10}$.

Integrar atividades acadêmicas com o mundo do trabalho no SUS foi um dos principais eixos da mudança do currículo. Desde as etapas iniciais do curso, os estudantes de Odontologia têm a oportunidade de experienciar atividades de ensino teórico-práticas de aproximação, 
conhecimento e vivência junto aos serviços públicos de saúde, que se intensificam no último ano da formação com o aumento expressivo da carga horária dos estágios curriculares no SUS. Os estágios foram implantados de forma progressiva, buscando propiciar aos estudantes do curso a inserção nos serviços de Atenção Primária à Saúde (APS), por meio da atuação em Unidades Básicas de Saúde e Unidades de Saúde da Família, assim como, em serviços de Gestão e Atenção Especializada na saúde bucal ${ }^{12}$.

No segundo semestre de 2009, a primeira turma formada no novo currículo concluiu sua graduação. Entendendo o currículo como algo que adquire forma e significado educativo à medida que sofre uma série de transformações no seu desenvolvimento e dentro das atividades práticas $^{13}$, o projeto de avaliação curricular do curso de Odontologia da UFRGS teve início, no segundo semestre de 2010.

$\mathrm{Na}$ primeira etapa do estudo, 360 estudantes do primeiro ao décimo semestre foram ouvidos em relação ao atual currículo (88,5\% do total de estudantes matriculados). Foram identificadas questões referentes ao conhecimento dos estudantes sobre a estrutura curricular e projeto pedagógico, planos de ensino, metodologias de ensino-aprendizagem, competências adquiridas ao longo da formação, avaliação da aprendizagem, disciplinas curriculares, seminários, clínicas integradas, estágios e trabalho de conclusão de curso ${ }^{14}$.

Dando continuidade ao processo de avaliação, a segunda e a terceira etapas da pesquisa envolveram, respectivamente, professores do curso, funcionários técnicos administrativos e gestores, todos atores do processo de mudança curricular. O presente artigo tem como objetivo analisar o desenvolvimento do currículo atual do curso de Odontologia da UFRGS na perspectiva de seus professores, técnicos administrativos e gestores, apresentando os resultados relativos a segunda e terceira etapas do projeto de avaliação curricular.

\section{METODOLOGIA}

A presente pesquisa assume a modalidade estudo de caso $^{15}$ como método de investigação, numa forma predominantemente qualitativa ${ }^{16}$, cujo campo de investigação foi o curso de graduação em Odontologia da Universidade Federal do Rio Grande do Sul (UFRGS), em Porto Alegre, Rio Grande do Sul.

Os sujeitos do estudo foram professores, funcionários técnicos administrativos e equipe diretiva do curso. Todos os professores foram convidados a participar da pesquisa. A seleção dos funcionários técnicos administrativos $\mathrm{e}$ gestores aconteceu de modo intencional, levando em consideração o objetivo proposto. Foi utilizado o método da 'amostragem por bola de neve', na qual o pesquisador faz uma entrevista em profundidade, com um sujeito indicado pela vivência pessoal e informações que este detém sobre o assunto pesquisado; em seguida, o entrevistador seleciona um segundo sujeito, o qual foi recomendado pelo primeiro a pedido do pesquisador e assim, sucessivamente, até o momento em que percebe não encontrar dados novos ${ }^{17}$. Ao final, fizeram parte do estudo 59 professores, sete técnicos administrativos e três gestores do curso de Odontologia $(n=69)$.

O corpus de análise constitui-se pela aplicação de um instrumento de coleta de dados - questionário semiestruturado - previamente testado, não identificado (para os professores) e da realização de entrevistas semiestruturadas (para os técnicos administrativos e gestores).

A elaboração do questionário foi baseada no projeto pedagógico do curso, na revisão de literatura realizada sobre o tema em estudo, e no instrumento de pesquisa aplicado aos estudantes do curso na primeira etapa da pesquisa. $O$ questionário foi composto por questões abertas e fechadas, contemplando os seguintes aspectos: perfil docente; sobre a reestruturação curricular; 
sobre o curso de Odontologia; sobre a prática docente e desafios/sugestões. Os professores receberam informações prévias sobre a realização do estudo e preenchimento do questionário enviado por correio eletrônico. Os questionários, assim, foram entregues aos professores, na forma impressa e, também, encaminhados por correio eletrônico, junto com os Termos de Consentimento Livre e Esclarecido. Os professores tiveram um período de 30 dias para preenchimento e entrega do material, depositando-o em uma urna disponibilizada em local discreto na recepção da Faculdade de Odontologia.

As entrevistas com os técnicos administrativos e equipe diretiva foram realizadas por um único pesquisador, seguindo um roteiro prétestado, de forma individual, gravadas em equipamento de áudio e integralmente transcritas. Todas as transcrições foram devolvidas aos entrevistados para que pudessem lê-las, verificando se estavam de acordo com as ideias apresentadas e, se julgassem necessário, complementassem seus relatos. A coleta de dados aconteceu entre 2012 e 2013.

Foram analisados, descritivamente, os dados de perfil docente e as respostas referentes às questões fechadas do questionário, por meio do software Statistical Package for the Social Sciences (SPSS). Já os dados qualitativos foram interpretados pelo método da análise de conteúdo ${ }^{18}$.

O estudo teve aprovação do Comitê de Ética em Pesquisa da Universidade (Projeto $n^{\circ}$ 20297).

\section{RESULTADOS E DISCUSSÃO}

Os protagonistas do estudo: perfil dos professores, técnicos administrativos e gestores

A percepção dos professores, responsáveis pela mediação do conhecimento e pelo processo de avaliação das aprendizagens, a respeito da implantação do novo currículo é de suma importância, pois, pela experiência cotidiana com os estudantes e pela atuação como mediadores do conteúdo, os docentes representam fonte significativa para uma avaliação das turmas de estudantes que ingressaram em um novo currículo ${ }^{19}$.

De um total de 113 professores vinculados ao curso de Odontologia da UFRGS no período do estudo, 59 (52,2\%) participaram dessa pesquisa de avaliação curricular. Destes, a maioria eram mulheres $(50,8 \%)$, com idade entre 29 e 38 anos $(52,5 \%)$, que exerciam atividades docentes em diferentes períodos do curso. Eram professores adjuntos $(71,2 \%)$, doutores $(96,6 \%)$, com carga horária de trabalho de 40 horas com dedicação exclusiva (74,5\%) (Tabela 1).

O estudo contou com a avaliação de professores de diferentes áreas, incluindo desde aquelas voltadas ao ensino clínico (Endodontia, Periodontia, Prótese, Cirurgia, Dentística, Materiais Dentários, Patologia Bucal/Estomatologia, Odontologia Preventiva, Radiologia, Ortodontia), até as de formação fundamental/básica (Ciências Biológicas - Biologia Molecular, Farmacologia; e Ciências Sociais - Saúde Coletiva, Saúde Pública, Epidemiologia, Sociologia, Psicologia).

Em relação aos técnicos administrativos, sete funcionários participaram das entrevistas, com idade entre 39 e 57 anos, todos apresentando ensino superior completo. Os três gestores do curso de Odontologia participantes do estudo fizeram parte tanto da construção quanto da implementação do currículo avaliado.

\section{Processo de reestruturação curricular: constru- ção coletiva de uma proposta de mudança na formação em saúde \\ Quando se fala em currículo, entra-se em} um campo intenso de discussão, uma vez que o currículo nunca é apenas um conjunto neutro de conhecimentos que de algum modo aparece nos documentos de referência e nas salas de aulas. É 
sempre parte de uma tradição seletiva, resultado da Por isso mesmo "é produto de tensões, conflitos $e$ escolha de alguém ou da visão de um determinado concessões culturais e econômicas que organizame grupo sobre o que seja um conhecimento específico. desorganizam um povo" (p. 59) ${ }^{20}$.

Tabela 1 - Perfil dos professores do curso de Odontologia que participaram do estudo.

\begin{tabular}{|c|c|c|}
\hline VARIÁVEIS & $\mathbf{n}$ & $\%$ \\
\hline \multicolumn{3}{|l|}{ SEXO } \\
\hline Feminino & 30 & 50,8 \\
\hline Masculino & 28 & 47,5 \\
\hline Não informou & 1 & 1,7 \\
\hline \multicolumn{3}{|l|}{ IDADE (ANOS) } \\
\hline 29 a 33 & 12 & 20,3 \\
\hline 34 a 38 & 19 & 32,2 \\
\hline 39 a 43 & 9 & 15,2 \\
\hline 44 a 49 & 4 & 6,8 \\
\hline 50 a 54 & 8 & 13,6 \\
\hline 55 a 59 & 3 & 5,1 \\
\hline 60 a 63 & 4 & 6,8 \\
\hline \multicolumn{3}{|l|}{ PERÍODO DO CURSO EM QUE ATUA } \\
\hline Início do curso $\left(1^{\circ}\right.$ ao $3^{\circ}$ semestre $)$ & 9 & 15,3 \\
\hline Início e meio do curso ( $1^{\circ}$ ao $7^{\circ}$ semestre $)$ & 11 & 18,6 \\
\hline Início e final do curso $\left(1^{\circ}\right.$ ao $3^{\circ} / 8^{\circ}$ ao $10^{\circ}$ semestre $)$ & 2 & 3,4 \\
\hline Meio do curso $\left(4^{\circ}\right.$ ao $7^{\circ}$ semestre $)$ & 16 & 27,1 \\
\hline Meio e final do curso $\left(4^{\circ}\right.$ ao $10^{\circ}$ semestre $)$ & 10 & 16,9 \\
\hline Final do curso $\left(8^{\circ}\right.$ ao $10^{\circ}$ semestre $)$ & 6 & 10,2 \\
\hline Durante todo o curso $\left(1^{\circ}\right.$ ao $10^{\circ}$ semestre $)$ & 5 & 8,5 \\
\hline \multicolumn{3}{|l|}{ CARGO } \\
\hline Adjunto & 42 & 71,2 \\
\hline Associado & 12 & 20,3 \\
\hline Titular & 3 & 5,1 \\
\hline Assistente & 1 & 1,7 \\
\hline Substituto & 1 & 1,7 \\
\hline \multicolumn{3}{|l|}{ TITULAÇÃO } \\
\hline Doutorado & 57 & 96,6 \\
\hline Mestrado & 2 & 3,4 \\
\hline \multicolumn{3}{|l|}{ ESTÁGIO PÓS-DOUTORADO } \\
\hline Não & 43 & 72,9 \\
\hline Sim & 7 & 11,9 \\
\hline Não respondeu & 9 & 15,2 \\
\hline \multicolumn{3}{|l|}{ REGIME DE TRABALHO } \\
\hline 20 horas semanais & 6 & 10,2 \\
\hline 40 horas semanais & 8 & 13,6 \\
\hline 40 horas - Dedicação Exclusiva & 44 & 74,5 \\
\hline Não respondeu & 1 & 1,7 \\
\hline TOTAL & 59 & 100,0 \\
\hline
\end{tabular}

No curso de Odontologia avaliado, pouco relatou ter participado do processo de mais da metade dos professores que responderam reestruturação curricular. Os demais ainda não ao instrumento de avaliação curricular $(54,2 \%)$ tinham vínculo de trabalho com a Universidade 
quando da mudança, ou seja, são professores que ingressaram após 2005. Dos professores que participaram, a maior parte afirmou que esta proposta foi construída de forma democrática, participativa, com espaço para contribuir, apresentando conflitos, mas também, com ampla participação da comunidade acadêmica.

"A reforma curricular foi construída de forma democrática. Os diferentes setores da faculdade foram convidados a participar $e$ houve diversos momentos de debate $e$ discussões". (Professor 22)

"Foi construída com participação democrática, mas com muitos conflitos devido ao entendimento diverso sobre o papel da Universidade na formação de profissionais de saúde. A lógica privatista influenciou estes conflitos, mas as diretrizes curriculares auxiliaram na determinação dos objetivos". (Professor 44)

Os técnicos, da mesma forma que os professores, relataram que o processo de reestruturação contou com a participação de todos os segmentos da comunidade acadêmica, com espaço para participação, sendo um momento de forte discussão na Faculdade de Odontologia.

"Eu me lembro das reuniões que aconteciam, dos professores externos que vinham conversar sobre o currículo. [...]. A proposta foi construída, sim, por toda a comunidade, tanto de alunos como de técnicos, técnicos sempre em pequeno número, mas dos professores e dos alunos com certeza, dos alunos também, mas todos os professores participaram das suas áreas dando os seus pensamentos...foi uma construção coletiva, com certeza". (Técnico administrativo 5)

"Tinham muitas reuniões com os professores, muitas discussões, muita gente a favor, muita gente contra. Foi um período bem turbulento porque tinha que fazer aquela mudança. [...] Momento de discussão muito forte na
Universidade”. (Técnico administrativo 6)

Os gestores também destacaram a importância da construção coletiva do processo para a efetividade da mudança, contando inclusive com a participação de outros setores da Universidade, como a Pró-Reitoria de Graduação (PROGRAD) e da parceria estabelecida com a Associação Brasileira de Ensino Odontológico (ABENO).

"[...] a construção do currículo que temos implantado desde 2005, para mim, é um divisor de águas no modelo de fazer da nossa faculdade. [...] a participação sempre foi muito intensiva. [...] eu entendi que a gente estava caminhando no sentido de fazer a Faculdade de Odontologia ser um centro de formação qualificada de atendimento que superasse o modelo mecanicista de Odontologia e que a gente pudesse trabalhar dentro da lógica da saúde. [...] a reforma curricular foi o motor que impulsionou a mudança de posicionamento político dentro da unidade. Isto realmente foi uma construção coletiva. [...] a gente chamava as pessoas e discutia, ouvia demandas, ouvia críticas, ouvia, e a coisa foi sendo construída por todos. Por todo mundo. Isso foi um dos aspectos mais bonitos da construção, ela foi em conjunto". (Gestor 2 )

"[...] desde 2002 que a gente vinha discutindo a mudança, e essa discussão se deu de forma ampla com toda a comunidade da faculdade e envolveu outros setores da Universidade, a própria PROGRAD na época esteve aqui, a ABENO esteve aqui. Isto é, teve uma construção que foi liderada pela COMGRAD que trouxe para dentro da comunidade da faculdade a discussão da adaptação às diretrizes, e essa adaptação a gente decidiu que seria uma mudança efetiva”. (Gestor 3)

A mudança na formação dos profissionais da saúde deve começar no próprio processo de construção do projeto pedagógico, que deve ser 
coletivo, baseado na reflexão crítica sobre as práticas tradicionais de aquisição de novos conhecimentos e possibilitando a participação do maior número possível de todos os envolvidos no cotidiano do currículo ${ }^{21}$.

Outra característica importante apontada pelo gestor do curso é que a mudança realizada não foi uma simples adaptação de um modelo 'antigo' para um 'novo', mas sim, uma mudança estrutural do currículo norteada pelo texto das DCN.

"Na época, eu me lembro que ficou decidido que a gente faria uma reforma geral, não seriam só algumas adaptações, então a gente fez um estudo do que as diretrizes estavam pedindo e tentou na hora de planejar, semestre a semestre, fazer um curso que tivesse o encadeamento de conteúdos no semestre e entre os semestres". (Gestor 1)

Feuerwerker $^{22}$ reitera que as mudanças no processo de formação profissional têm que ser profundas, não podem ser mudanças de fachada, de simples rearranjos de cargas horárias ou introdução de novas disciplinas. E, mudanças assim, profundas e estruturais, como a proposta pela Odontologia da UFRGS, muitas vezes criam mais resistências do que adesões, sendo fundamental criar uma base comum de diálogo e discussão entre seus protagonistas. Longe de ser um ato neutro, "fazer currículo, é um ato de comprometimento e filiação social de uma particular comunidade ocupacional" (p. 351) ${ }^{23}$.

Estas resistências também marcaram as mudanças curriculares nessa Universidade, especialmente no que referiu à proposta de trabalho integrado nas clínicas odontológicas.

"Não era a forma de trabalho usual e no início muitas pessoas tiveram resistência, não queriam, não compareciam às reuniões. Assim, eu me lembro que dois anos consecutivos a gente ficou trabalhando em cima disso, até que as pessoas foram se engajando, foram entendendo o que as diretrizes estavam pedindo, que na verdade mudava bastante o perfil do profissional formado neste modelo. Houve muita resistência, especialmente pelos professores da área clínica, em que havia toda uma argumentação de que se perderia qualidade, que os alunos efetivamente não teriam a formação planejada”. (Gestor 1)

O currículo deve ser pensado como algo complexo, que não se dá em uma "única lógica, que não se estabelece a partir de explicações simples ou de relações permanentes, simplesmente previstas, planejadas e previsivelmente controladas" (p. 146) $)^{24}$.

As resistências, assim, não devem ser vistas como uma fragilidade da proposta, mas sim, como uma reação necessária e até esperada, já que o conflito remete ao refinamento, revisão, criação de ideias, problematização, prevenindo a cristalização e o dogmatismo de um paradig$\mathrm{ma}^{25}$.

\section{A consolidação do currículo e os avanços con- quistados a partir da reestruturação curricular}

O currículo se dinamiza na prática educativa como um todo, e nela assume feições que o conhecimento e a compreensão do documento por si só não permitem elucidar ${ }^{26}$.

No contexto da prática do desenvolvimento curricular, $64,4 \%$ dos professores relataram conhecer bem a estrutura do currículo e 47,4\% conheciam, já leram alguma coisa sobre o Projeto Pedagógico do curso de Odontologia (Tabela 2).

Dos sete técnicos administrativos ouvidos, dois responderam conhecer bem a estrutura curricular e o projeto pedagógico do curso, quatro conhecem um pouco e um afirmou não conhecer.

Estudo realizado com os estudantes da $1^{\mathrm{a}}$ à $10^{\mathrm{a}}$ etapa no curso de Odontologia da UFRGS, avaliando o atual currículo, mostrou que a maior parte deles não conhecia a proposta curricular ao 
ingressarem no curso $(78,6 \%)$ e que esta foi apresentada ao chegarem à Universidade $(81,4 \%)$.

Mais de $50 \%$ dos estudantes afirmou conhecer bem a estrutura curricular do curso, e $34,2 \%$ conhecia um pouco/já tinha lido alguma coisa sobre o projeto pedagógico ${ }^{14}$.

Tabela 2 - Conhecimento dos professores sobre o currículo e projeto pedagógico do curso de Odontologia.

\begin{tabular}{ccc}
\hline VARIÁVEIS & n & \% \\
\hline CONHECIMENTO DO CURRÍCULO & 38 & 64,4 \\
Sim, conhece bem & 19 & 32,2 \\
Conhece pouco & 2 & 3,4 \\
Desconheço & & \\
CONHECIMENTO DO PROJETO PEDAGÓGICO APÓS A & & \\
REESTRUTURAÇÃO CURRICULAR & 23 & 39,0 \\
Conhece bem & 28 & 47,4 \\
Conhece, já leu alguma coisa & 6 & 10,2 \\
Apenas ouviu falar & 2 & 3,4 \\
\hline Não conhece e não sabe qual seu conteúdo & $\mathbf{5 9}$ & $\mathbf{1 0 0 , 0}$ \\
\hline TOTAL & &
\end{tabular}

Quando questionados se o curso de Odontologia possibilita uma formação que prepare o estudante para atuar no mercado do trabalho, a maioria dos professores entende que sim $(81,3 \%)$. O mesmo foi percebido pelos técnicos e gestores. É um estudante que conclui sua graduação preparado tanto para atuar tanto nos serviços públicos de saúde quanto nos privados.

“A Odontologia proporciona uma formação completa e integrada. O aluno sai com bases sólidas para atuar no mercado de trabalho". (Professor 9)

"Se ele (o estudante) quiser, ele pode sair daqui muito mais preparado para uma vida profissional, seja inserido em saúde pública, em sistemas públicos de saúde ou em uma clínica privada, do que antes". (Técnico administrativo 7)

"Eu tenho segurança que o nosso aluno sai qualificado podendo trabalhar e podendo se comportar num ambiente de clínica privada com competência e podendo trabalhar em um ambiente de serviço público, conhecendo o Sistema Único de Saúde na sua essência e trabalhando. Tanto é que a grande maioria dos aprovados nas residências mul- tiprofissionais são da nossa faculdade, isso é um ganho na formação enorme”. (Gestor 2)

Esta mesma percepção positiva em relação à formação para atuar no mercado de trabalho foi relatada por $85,3 \%$ estudantes de Odontologia da UFRGS $^{14}$.

No que se referiu às maiores ênfases do curso de Odontologia, os professores destacaram a formação generalista, ampliada e integral, ênfase na Saúde Coletiva/ Saúde Pública/ Odontologia Social/ Formação para o SUS e a formação em áreas específicas. Já para os técnicos, as maiores ênfases do curso são a formação integral, a Saúde Coletiva, a formação em áreas específicas e a formação generalista/clínico geral.

Enfases semelhantes foram observadas pelos estudantes do curso, destacando a Saúde Pública/Saúde Coletiva/SUS, as disciplinas específicas e a formação com ênfase no humano/saúde como um todo ${ }^{14}$.

Os professores perceberam mudanças a partir da reestruturação curricular em relação aos seguintes aspectos: integração curricular entre professores de diferentes departamentos e entre as áreas (interdisciplinaridade), estudantes mais humanizados, metodologias de ensino que 
permitem espaço para mais discussão, melhorias no atendimento aos pacientes, atividades didáticas diversificadas e estágios curriculares no SUS.

"Integração com colegas, paciente mais bem atendido, aluno mais humanizado, metodologias de ensino que permitem espaço para mais discussão”. (Professor 2)

"[...] atividades integradoras de várias áreas, atividades didáticas diversificadas como seminários, casos clínicos, etc." (Professor 54)

"[...] o aluno acompanha o paciente de acordo com suas necessidades e de forma mais integrada. Estágios em serviço do SUS é o mais positivo!"' (Professor 34)

A integração curricular, prevista desde o início do curso, por meio dos Seminários de Integração e dos Acompanhamentos Clínicos e na sequência curricular, pelas Clínicas Integradas do $5^{\circ}$ ao $8^{\circ}$ semestre, também foi destacada na fala dos gestores do curso.

"[...] trabalhar integrado, mas para trabalhar integrado tu tens que trabalhar desde o início do curso, tu não podes pensar em integrar quando tu aprendeu aos pedaços, então tem que começar integrado desde o primeiro momento, então, os seminário de integração, os acompanhamentos clínicos eram formas de viabilizar este modelo, de construir conhecimento que deixasse o aluno no último ano capaz de ir para o cenário de prática do SUS com segurança de que aquele espaço, é um espaço legal pra ele." (Gestor 2) "Eu vou enumerar algumas coisas que deram certo: primeiro: um grande temor que a gente tinha era com o final das disciplinas específicas (perio, dentística, endo), que isso levaria ao extermínio da área do conhecimento, nada mais equivocado. $O$ que eu percebo hoje é que as áreas como perio, dentística, endo, estão mais fortes hoje do que eram na época em que elas tinham aquele domínio, aquele monopólio. Claro que obrigou as pessoas a estudar. Acho que uma grande vantagem, hoje, é o convívio nas clínicas, um convívio muito interessante para o professor. Com isso houve uma integração maior da docência, um reforço das áreas de conhecimento, e quem realmente ganha com isso é o aluno, porque o aluno tem uma oportunidade de trabalhar integradamente [...] não havia pacientes na faculdade, havia necessidades, e hoje eu acho que tem o conceito de paciente, o que eu ouço, o que as pessoas falam em pacientes, no meu paciente, não mais naquele molar que eu preciso fazer diagnóstico de pulpite." (Gestor 3)

As DCN estabelecem a integração curricular como condição essencial da estrutura do curso de graduação em Odontologia ${ }^{7}$. O ensino baseado na integração proporciona uma aprendizagem mais estruturada e rica, pois os conceitos estão organizados em torno de estruturas conceituais e metodológicas compartilhadas por várias disciplinas ${ }^{27}$.

Segundo Anastasiou ${ }^{28}$, as ações integrativas auxiliam o estudante a construir um quadro teórico-prático global mais significativo e mais próximo dos desafios presentes na realidade profissional dinâmica e única, na qual atuará depois de concluída a graduação.

Essa abordagem interdisciplinar da construção do conhecimento na formação em saúde implica em ultrapassar "as fronteiras entre as disciplinas - espaços de confinamento por excelência - e a articulação dos processos de ensino-aprendizagem ao trabalho e à pesquisa" (p. 262) ${ }^{29}$.

$\mathrm{Na}$ percepção dos técnicos, as mudanças curriculares mais significativas aconteceram em relação aos estágios curriculares extramuros que passaram a enfatizar a integração ensino-serviçocomunidade, acontecendo em cenários de prática do SUS (serviços de APS, de média e alta complexidade e gestão em saúde pública) e nas 
clínicas, que eram organizadas por especialidade e passaram a se constituir por complexidade de procedimentos, prevendo a integração entre as diferentes áreas do conhecimento, com ênfase nas necessidades do paciente.

"[...] no último semestre os alunos faziam um estágio de saúde coletiva no módulo, que era fora da Universidade, eles diziam que era extramuros, mas era só uma clínica que não funcionava aqui dentro. Com a vinda do novo currículo abriram-se os campos de estágios na rede do SUS, e com isso se esgotou aquele modelo. A integração das clínicas também, isso é uma coisa muito positiva, que as áreas começaram a se falar." (Técnico administrativo 1)

"Eu percebo uma integração maior entre as diferentes disciplinas, os diferentes setores, é perceptível uma interação maior entre as diferentes áreas do conhecimento e eu, particularmente, acho muito positivo. $O$ que eu vejo quando eu passo pelas clínicas e que é uma coisa muito bacana é uma série de professores de diferentes áreas dando cobertura ao atendimento. Não é mais aquela forma de tratar por especialidade e cada um olhando para o seu quadrado sem olhar a boca inteira." (Técnico administrativo 7)

Outro aspecto do currículo ressaltado pelos técnicos como um diferencial importante para a atuação profissional do cirurgião-dentista foi a inclusão de conteúdos da área das Ciências Humanas e de Gestão em Saúde.

"[...] é uma mudança muito grande pensar que tu não vem mais só pra aprender a técnica e a pesquisa sobre aquela área, que é muito importante esse lado tecnológico da odontologia, enfim, mas outra área que é a área de humanas e a área da gestão em saúde também e que são outras capacidades que eles precisam desenvolver para o mundo do trabalho e que estavam muito afastados disso." (Técnico administrativo 4)
Avaliação realizada na Universidade Federal da Paraíba sobre o perfil do estudante de Odontologia formado a partir de 2002, por um currículo adequado às $\mathrm{DCN}$, mostrou que os estudantes consideraram importante para $\mathrm{o}$ exercício profissional as disciplinas que envolviam as Ciências Humanas ${ }^{30}$.

As Ciências Humanas na educação em Odontologia constituem-se, ao mesmo tempo, um caminho complexo e fértil para um projeto de humanização que tem o homem como objeto central de reflexão. Seu papel nos currículos é pensar a finalidade e a qualidade da existência humana para além do simples alongamento de sua duração ou bem-estar baseado no consumo e nas metas pré-estabelecidas dos agentes financeiros internacionais ${ }^{31}$.

Em relação ao perfil de formação do estudante, os professores perceberam as seguintes mudanças: humanização/saberes humanísticos, ética, interesse e conhecimento pela Saúde Pública/ Saúde Coletiva/ SUS, maior entendimento multiprofissional, conhecimento técnico, prática integral/ integralidade, formação generalista com perfil mais amplo, focado nas necessidades do sujeito/paciente.

"Humanização, interesse por saúde pública, maior entendimento de multiprofissionalidade." (Professor 2)

"A busca pelo conhecimento técnico de excelência convive com naturalidade com a busca pelos saberes humanísticos assim como o saber em saúde coletiva assumiu um papel central na formação dos estudantes." (Professor 7)

"O estudante é formado no conceito da integralidade, identificado com sua realidade social, expressão humanista e ética de acordo com o perfil traçado pelo projeto da faculdade." (Professor 54)

Essa mesma percepção foi destacada pelos técnicos e gestores, os quais observaram mudanças no perfil dos estudantes quanto aos 
aspectos relacionados à formação clínica atuando em todas as clínicas não de forma fragmentada, isolada por especialidades, e sim de modo integrado, realizando diferentes procedimentos de acordo com a necessidade do paciente - e a integração das atividades acadêmicas com o mundo do trabalho no SUS.

"O que eu vejo é que todos os alunos, de uma forma geral, eles modificaram a sua postura. Hoje eu vejo o aluno, semana num paciente fazendo endo, no outro paciente fazendo raspagem, no outro restaurando, na sequencia apresentando um plano de tratamento multidisciplinar." (Técnico administrativo 5)

"Percebo nitidamente diferença. No modelo antigo o aluno era realmente preparado para ir para dentro de um consultório, exercer clínica privada, isso é bem nítido e partir deste modelo novo, a visão que se dá para este aluno e o modelo de profissional, o perfil profissional, tem se voltado para a rede pública e eu vejo que este aluno tem realmente uma visão diferente. Isso eu consigo concretizar, materializar que é assim, através das conversas com os alunos." (Gestor 1 ).

Corroborando com essas evidências em relação às mudanças no perfil do cirurgiãodentista que vivenciou o currículo integrado, os estudantes do curso apontaram como potencialidades da formação a ênfase na humanização da saúde e o período dos estágios curriculares supervisionados no SUS ${ }^{14}$.

É preciso compreender que as transformações nos processos educativos não se constroem simplesmente na prática pedagógica, no papel, em 'ambientes especiais', como as clínicas das faculdades de Odontologia, mas sim em todos os cenários nos quais se dá a prática profissional, enfrentando problemas que se apresentam nas realidades, permitindo reflexão e propondo mudanças ${ }^{32}$. Além da capacidade e habilidade técnica de tratamento de doenças, é imprescindível que os profissionais sejam capazes de produzir níveis crescentes de saúde na população. Assim, a vivência dos profissionais em todos os espaços onde possa ser produzida a saúde, torna-se uma exigência, sobretudo, se o objetivo é formar profissionais aptos para atuar no SUS ${ }^{33}$.

Ceccim e Feuerwerker ${ }^{34}$ argumentam que a atualização técnico-científica é apenas um dos aspectos da qualificação do profissional da saúde e deve englobar aspectos de produção de subjetividade, produção de habilidades técnicas e de pensamento, além do adequado conhecimento sobre o SUS.

A integração ensino-serviço é um dos eixos que busca concretizar as mudanças curriculares por meio de ações diversas na interface do ensino com o serviço ${ }^{35}$. É uma forma de experiência educacional na qual os estudantes se engajam em atividades que abordam as necessidades do homem e da comunidade, em conjunto com as oportunidades intencionalmente estruturadas para promover a aprendizagem e o desenvolvimento dos estudantes ${ }^{36}$.

Nessa perspectiva, a inserção dos estudantes de graduação nos serviços do SUS, tem se constituído uma estratégia de grande potencial para a integração da teoria com práticas colaborativas e interprofissionais na formação dos profissionais da saúde ${ }^{37}$.

No Brasil, o ensino integrado aos serviços públicos de saúde por meio de estágios curriculares tem contribuído para a formação do cirurgião-dentista pela possibilidade do ganho clínico associada com o estabelecimento de vínculos com os pacientes e equipe de saúde, fortalecimento da autonomia para a resolução de problemas/tomada de decisões, comunicação, trabalho em equipe multiprofissional nos serviços de APS, mudança na compreensão sobre as redes de atenção à saúde e o desenvolvimento da competência cultural ${ }^{30,38,39,40}$.

Por fim, experiências de aprendizagens que 
promovam a cidadania, também se destacaram como um diferencial na formação deste estudante de Odontologia.

"No modelo curricular anterior a gente nem pensava na formação da cidadania, pensava só na formação profissional, agora não, ele é um cidadão que tem uma atividade profissional. Como cidadão ele tem algumas tarefas, daí entram as competências que ele tem que desenvolver. Às vezes eu vou nas atividades do estágio 1 do estágio 2 e eu vejo o amadurecimento dos alunos, como eles estão inseridos como profissional e como cidadão e isto eles adquiriram aqui dentro." (Gestor 1).

O estímulo ao desenvolvimento da cidadania, entendida como um conjunto de atitudes e valores correspondentes à ética profissional e ao compromisso com a sociedade está presente no texto das $\mathrm{DCN}^{7}$, deve fazer parte de processos educativos dos profissionais da saúde e da própria universidade que pretenda ser socialmente responsável ${ }^{41}$.

Professores, técnicos e gestores entendem que a mudança curricular trouxe ganhos importantes para todos os seus participantes especialmente os usuários - melhorou em relação ao currículo anterior, mas não é um processo acabado. Está em constante transformação e deve ser aprimorado, o que passa, necessariamente, pela qualificação do corpo docente e pelo apoio da equipe diretiva.

"O atual currículo do curso tem uma estrutura muito adequada para dar conta do que preconizam as Diretrizes Curriculares Nacionais, o que me motiva para atuar cada vez mais, como uma facilitadora dessa estrutura curricular. Mas também vejo a necessidade de avançarmos na proposta. Isso passa pela capacitação contínua do corpo docente e pelo apoio incondicional da equipe diretiva da Faculdade." (Professor 5)

"É um currículo em construção permanente, que permanentemente ele pode e deve ser alterado, acho que melhorou muito em relação ao currículo passado, a gente perdeu aquele feudalismo das áreas, uma em cada dia [...] a sociedade, que é o nosso usuário final, ganha com isso." (Técnico administrativo 5)

"[...] certamente houve benefícios, mas o processo é permanente, a avaliação é permanente, não existe um fim para o modelo. [...] A transformação é permanente. Não tem currículo estabelecido, tem currículo em construção. Quem pensar em currículo estabelecido já perdeu a mão. Tem que haver mudança, e aí aproveitar o pessoal mais novo, buscar essas novas metodologias e novos recursos de ensino." (Gestor 3 )

\section{Vivenciando o currículo: um processo contínuo de aprendizagens e desafios}

Buscar o novo na organização curricular é desejável. A inovação é essencial em toda

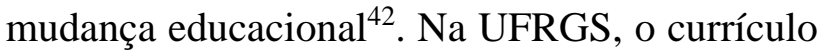
do curso de Odontologia modificado a partir das $\mathrm{DCN}$, incorporou aspectos estruturais e pedagógicos inovadores na trajetória acadêmica do estudante. A vivência nesse currículo mostrou importantes mudanças que permitiram qualificar ainda mais a formação do cirurgião-dentista egresso. Com os avanços, desafios também foram observados.

Os desafios mais apontados pelos professores no desenvolvimento curricular referiram-se à integração entre as disciplinas, entre as áreas do conhecimento e entre teoria e prática, à qualificação docente para atuação nessa proposta curricular e à necessidade de discussão continuada dos resultados da avaliação curricular, com avanços em questões específicas, tais como avaliação dos estudantes, melhoria nas condições de trabalho, integração nas disciplinas/ clínicas/ estágios.

"Muito já se avançou com a atual proposta 
curricular da Odontologia. Discute-se, hoje, questões que há uns poucos anos, nem eram mencionadas. Mas a proposta é processual, precisa de um tempo até que as mudanças pretendidas se concretizem na prática, na rotina da formação. Entendo, desse modo, que precisamos avançar na integração nas disciplinas/Clínicas/ Estágios e entre elas, na proposta de avaliações baseadas em processos de aprendizagem, nas capacitações docentes e em avaliações constantes do currículo." (Professor 5)

Sugeriram, além disso, uma maior integração entre professores da Odontologia com os professores dos demais cursos da saúde na Universidade.

"Achei importante a direção e professores de Odontologia se integrarem em projetos com outros cursos, creio que ainda falta estimularmos nossos alunos a participarem desse processo, bem como os professores das clínicas e disciplinas de início de curso. $O$ fato da Comissão de Graduação do curso participar e apoiar a constituição da Disciplina Integradora com os outros cursos de saúde também considero relevante." (Professor 44)

Para os técnicos, resistências em relação ao atual modelo curricular integrado em áreas específicas e articulado ao SUS - 'velhas' práticas - são os maiores desafios a serem enfrentados para a consolidação da proposta curricular.

"[...] algumas áreas de resistência. Eu acho que mesmo com a implementação do currículo e a proposta da integração, não são todas as áreas que estão completamente integradas ou atuando de uma forma que é realmente proposta, isso eu percebo. A integração não está concluída, eu enxergo como uma coisa que andou muito, mas que ainda não está concluída, que ainda falta para haver realmente a integração ou a interdisciplinaridade e outra coisa que eu acho que é um desafio, mas não é um desafio única e exclusivamente do currículo, mas é isso, no local de ensino, isso que a gente acabou de ver, com essa senhora que veio aqui e com outras pessoas que vem aqui, que é o desafio de aliar um lugar de ensino que precisa de determinadas coisas, de determinadas, digamos assim, lesões, de doenças pra tratar de forma hierárquica, em termos de complexidade, mas às vezes as pessoas, as pessoas que buscam o atendimento aqui e que ao mesmo tempo a escola precisa delas, elas vão ficando pra trás porque elas não estão na complexidade que se precisa... isso é um nó, isso é um grande nó que vem de muitos anos, aliar o ensino com a necessidade real da população no serviço." (Técnico administrativo 7)

Essa mesma dificuldade na integração curricular foi percebida pelos estudantes do curso que a compreendem em processo de construção $^{14}$.

Entendendo que reestruturações curriculares acontecem em processo, pode-se afirmar que o contexto apresentado no curso de Odontologia da UFRGS é favorável à mudança de perfil do cirurgião-dentista formado a partir das DCN. No entanto, somente haverá aprendizado a partir de reconhecimento e da compreensão das falhas ${ }^{43}$ e da noção de que espaço ocupa o conhecimento no currículo (conhecimento em si ou conhecimento para fazer algo $)^{44}$. A efetivação dessa mudança requer uma atitude crítica dos que desenvolvem e vivenciam cotidianamente o currículo, ajudando a olhar a situação de maneira mais abrangente, com sensibilização e mobilização.

"Os processos de emancipação são estimuladores de intervenções compromissadas com as rupturas que atuam no sentido de mudança. Não são medidos pelo tamanho e abrangência, mas sim pela profundidade e 
significado que têm para os sujeitos envolvidos. São difíceis de dimensionar objetivamente, pois atuam nos espaços de subjetividade e necessitam um tempo de maturação para poder produzir efeitos, que podem ser múltiplos e heterogêneos" ( $\mathrm{p}$. $17)^{45}$.

\section{CONSIDERAÇÕES FINAIS}

Os resultados encontrados mostram evidências positivas no perfil do cirurgiãodentista formado pelo currículo do curso de Odontologia estudado, qualificando-o nos seguintes aspectos: ensino integrado que possibilita a articulação entre professores de diferentes departamentos e de diferentes disciplinas (interdisciplinaridade), cuidado humanizado em saúde centrado nas necessidades do indivíduo/paciente com estímulo à cidadania dos estudantes, ensino clínico integrado organizado por complexidade de procedimentos e estágios supervisionados em cenários de prática do SUS.

A integração curricular, um dos eixos estruturantes da mudança proposta e reconhecida como uma potencialidade, também se estabeleceu como um desafio para a consolidação do processo. A qualificação docente para a atuação neste currículo aliada à possibilidade de discussão continuada dos resultados da avaliação curricular foram aspectos destacados para o fortalecimento do curso e que merecem a atenção da comunidade acadêmica, já pensando em novas propostas de mudanças na estrutura curricular vigente.

A visão das potencialidades e desafios apresentados e discutidos em relação ao currículo integrado do curso de Odontologia aqui analisado aponta para a necessidade de se repensar permanentemente tal currículo. Não é um currículo acabado e sim vivo, em processo de construção/reconstrução, o que favorece práticas educacionais cada vez mais renovadas e democráticas.

\section{ABSTRACT \\ Curriculum changes in higher education in Dentistry: innovations, resistance and obtained advances}

This article analyzes the development of an integrated curriculum of Dentistry guided by the National Curriculum Guidelines and based on skills in a public university from the southern of Brazil. The articulation of academic activities with the work world in the Unified Health System (SUS) was one of the major changes in this curriculum proposal. The method of research was predominantly qualitative, characterized as a case study. The application of questionnaires and conducting of semi-structured individual interviews composed the analysis corpus. The study included 59 teachers, seven administrative staff and three managers of the course. The results qualify the curriculum evaluated about the integration between teachers from different departments and among other areas (interdisciplinarity); humanized care in health focused on the needs of the individual/patient; incentive to citizenship; integrated clinical teaching, organized by complexity of procedures; and supervised internships in the SUS practice scenarios (primary care, medium and high complexity services, as well as health management). The curriculum integration, one of the main principles in the curriculum, was recognized as a potentiality, but also was established as a challenge to the process of consolidation. The teaching qualifications to act in this curriculum, as well as the continuing curriculum evaluation, were aspects that stood out for the strengthening of the course. Strengths and challenges were presented and discussed in relation to an integrated curriculum model in dentistry, pointing to the need of permanently rethink this curriculum, promoting educational practices renewed and democratic.

Descriptors: Educational Measurement. Curriculum. Education, Higher. Education, Dental. 


\section{REFERÊNCIAS}

1. Santomé JT. Evitando o debate sobre a cultura no sistema educacional: como ser competente sem conhecimento. In: Sacristán JG, Gómez ALP, Rodríguez JBM, Santomé JT, Rasco FA, Méndez JMA. Educar por competências: o que há de novo? Porto Alegre: Artmed; 2008. p.160-97.

2. Moreira AFB (Org). Currículo: questões atuais. 18a ed. Campinas; 2012. p. 7.

3. Costa EM de MB, Bara MTF, Garcia TA. Momentos de avaliação e movimentos de mudança em um curso de Farmácia. Avaliação. 2013;18(3):613-28.

4. Fagundes NC, Burnham TF. Discutindo a relação entre espaço e aprendizagem na formação de profissionais de saúde. Interface Comun Saúde Educ. 2005; 9(16) :105-14.

5. Feuerwerker LCM, Almeida M. Diretrizes Curriculares e projetos pedagógicos: é tempo de ação! Rev ABENO. 2004;4(1):14-6.

6. Forte FDS, Fernandes Pessoa TRR, Morais Freitas CHS, Pereira CAL, Carvalho Junior PM. Reorientação na formação de cirurgiões-dentistas: o olhar dos preceptores sobre estágios supervisionados no Sistema Único de Saúde (SUS). Interface Comun Saúde Educ. 2015;19(Supl 1):83143.

7. Resolução CNE/CES 3/2002, de 19 de fevereiro de 2002. Institui Diretrizes Curriculares Nacionais do Curso de Graduação em Odontologia. Diário Oficial da União, 4 mar 2002.

8. Ministério da Educação. Lei n ${ }^{\circ} 9.394$, de 20 de dezembro de 1996. Estabelece as diretrizes e bases da educação nacional. Diário Oficial da República Federativa do Brasil, Brasília, 23 dez 1996.

9. Carvalho ACP. Ensino de Odontologia no Brasil. In: Carvalho ACP, Kriger L. Educação odontológica. São Paulo: Artes Médicas; 2006. p. 5-15.

10. Universidade Federal do Rio Grande do Sul. Faculdade de Odontologia. Projeto Político Pedagógico. Porto Alegre; 2005

11. Le Boterf, G. Desenvolvendo a competência dos profissionais. Porto Alegre:
Artmed; 2003.

12. Warmling CM, Rossoni E, Hugo FN, Toassi RFC, Lemos VA, et al. Estágios curriculares no SUS: experiências da Faculdade de Odontologia da UFRGS. Rev ABENO. 2011;11(2):63-70.

13. Sacristán JG. Aproximação ao conceito de currículo. In: Sacristán JG. O currículo: uma reflexão sobre a prática. 3 a ed. Porto Alegre: Artmed; 2000. p. 13-53.

14. Toassi RFC, Souza JM De, Baumgarten A, Rösing CK. Avaliação curricular na educação superior em odontologia: discutindo as mudanças curriculares na formação em saúde no Brasil. Rev ABENO. 2012;12(2):170-7.

15. Yin R. Estudo de caso: planejamentos e métodos. 4a ed. Porto Alegre: Bookman, 2010.

16. Tong A, Sainsbury P, Craig J. Consolidated criteria for reporting qualitative research (COREQ): a 32-item checklist for interviews and focus groups. Int $\mathrm{J}$ Qual Health Care. 2007;19(6):349-57.

17. Turato ER. Tratado de metodologia da pesquisa clínico-qualitativa: construção teórico-epistemológica, discussão comparada e aplicação nas áreas da saúde e humanas. 3a ed. Petrópolis, RJ: Vozes; 2008.

18. Bardin L. Análise de conteúdo. São Paulo: Edições 70; 2011.

19. Abreu Neto IP, Lima Filho OS, Silva LEC, Costa NMDSC. Percepção dos professores sobre o novo currículo de graduação da Faculdade de Medicina da UFG implantado em 2003. Rev Bras Educ Méd. 2006;30(3):154-60.

20. Apple M. A política do conhecimento oficial: faz sentido a ideia de um currículo nacional? In Moreira AF, Silva TT. Currículo, cultura e sociedade. São Paulo: Cortez; 1994, p. 59-91.

21. Araújo ME, Zilbovicius C. A formação para o trabalho no Sistema Único de Saúde (SUS). In: Moysés ST, Kriger L, Moysés SJ (Coord). Saúde bucal das famílias: trabalhando com evidências. São Paulo: Artes Médicas; 2008. p. 277-90.

22. Feuerwerker LCM. A construção de sujeitos 
no processo de mudança da formação dos profissionais de saúde. Divulg Saúde Debate. 2000;22:18-24.

23. Domingues JL. Interesses humanos e paradigmas curriculares. Rev Bras Est Pedag. 1986;67(156): 351-66.

24. Padilha PR. Currículo intertranscultural: novos itinerários para a educação, São Paulo: Cortez; Instituto Paulo Freire; 2004.

25. Pacheco JA. Currículo: teoria e práxis. 2a ed., Portugal: Porto; 2001.

26. Macedo RS. Currículo: campo, conceito e pesquisa. Petrópolis, RJ: Vozes; 2007.

27. Audy JLN. Interdisciplinaridade e complexidade na construção do conhecimento: o desafio da integração ensino-pesquisa. In: Engers MEA, Morosini MC (Org). Pedagogia universitária. Porto Alegre: EDIPUCRS; 2007. p. 31-7.

28. Anastasiou LGC. Da visão de ciência à organização curricular. In: Anastasiou LGC, Alves LP. Processos de ensinagem na universidade: pressupostos para as estratégias de trabalho em aula. 5a ed. Joinville: UNIVILLE; 2005. p. 40-63.

29. Albuquerque VS, Batista RS, Tanji S, Moc̈o ETSM. Currículos disciplinares na área de saúde: Ensaio sobre saber e poder. Interface Comun Saúde Educ. 2009;13(31):261-72.

30. Cavalcanti YW, Cartaxo RO, Padilha WWN. Educação odontológica e sistema de saúde brasileiro: práticas e percepções de estudantes de graduação. Arq Odontol. 2010; 46(4): 224-31.

31. Moysés SJ. A humanização na educação em odontologia. Pró-Posições. 2003;14(1):87106.

32. Araujo ME. Palavras e silêncios na educação superior em odontologia. Ciênc Saúde Coletiva. 2006;11:179-82.

33. Morita MC, Haddad AE. Interfaces da área da educação e da saúde na perspectiva da formação e do trabalho das equipes de saúde da família. In Moysés ST, Kriger L, Moysés SJ (Coord). Saúde bucal das famílias: trabalhando com evidências. São Paulo: Artes Médicas; 2008. p. 268-76.

34. Ceccim RB, Feuerwerker LCM. O quadrilátero da formação para a área da saúde: ensino, gestão, atenção e controle social. Physis (Rio J). 2004;14(1):41-65.

35. Souza AL, Carcereri DL. Estudo qualitativo da integração ensino serviço em um curso de graduação em Odontologia. Interface Comun Saúde Educ. 2011;15(39):1071-84.

36. Hood JG. Service Learning in Dental Education: Meeting Needs and Challenges. J Dent Educ. 2009; 73(4):454-63.

37. Forte FDS, Morais HGF, Rodrigues SAG, Santos JS, Oliveira PFA, Morais MST, et al. Educação interprofissional e o programa de educação pelo trabalho para a saúde/ Rede Cegonha: potencializando mudanças na formação acadêmica. Interface Comun Saúde Educ. 2016;20(58):787-96.

38. Toassi RFC, Davoglio RS, Lemos VMA. Integração ensino-serviço-comunidade: o estágio na atenção básica da graduação em Odontologia. Educ Rev. 2012;28(4):223-42.

39. Toassi, RFC, Baumgarten A, Warmling CM, Rossoni E, Rosa, AR, Slavutzky SMB. O ensino nos serviços de Atenção Primária à Saúde do Sistema Único de Saúde (SUS) na formação de profissionais de saúde no Brasil. Interface Comun Saúde Educ. 2013; 17(45):385-92.

40. Bulgarelli AF, Souza KR, Baumgarten A, Souza JM, Rosing CK, Toassi RFC. Formação em saúde com vivência no Sistema Único de Saúde (SUS): percepções de estudantes do curso de Odontologia da Universidade Federal do Rio Grande do Sul (UFRGS), Brasil. Interface Comun Saúde Educ. 2014;18(49):351-62.

41. Page L, Chen V, Gibson B, McMillan J. Overcoming structural inequalities in oral health: the role of dental curricula. Com Dent Health. 2016;33:168-72.

42. Fernández T. O Docente Inovador. In: De La Torre S, Barrios O. Curso de formação para educadores. São Paulo: Madras; 2002.

43. Mckernan J. Currículo e imaginação: teoria do processo, pedagogia e pesquisa-ação. Porto Alegre: Artmed; 2009, p. 238-59.

44. Macedo E. Base nacional curricular comum: a falsa oposição entre conhecimento para fazer algo e conhecimento em si. Educ Rev. 2016;32(2):45-67. 
45. Cunha MI (Org). Pedagogia universitária: energias emancipatórias em tempos neoliberais. Araraquara, São Paulo: Junqueira \& Martin; 2006. p. 13-30.
Correspondência para:

Ramona Fernanda Ceriotti Toassi

e-mail: ramona.fernanda@ufrgs.br Faculdade de Odontologia da UFRGS Rua Ramiro Barcelos 2492, 2o andar 90035-003 Porto Alegre, RS 